\title{
Research on the Precision Straightening Stroke of SAE 52100 Steel in Different Heat Treatments
}

\author{
MI Aye Su Khaing*, LU Hong \\ School of Mechanical and Electronic Engineering, Wuhan University of Technology, Wuhan, China \\ *Corresponding author: ayesukhaing13@gmail.com
}

Received January 31, 2014; Revised February 25, 2014; Accepted March 13, 2014

\begin{abstract}
This research is aimed to analyze the microstructure and hardness properties of SAE 52100 steel straightening strokes based on experimental and theoretical investigation with different cross sectional shapes based on different heat treatment conditions. The heat treated samples are used for the design and manufacturing of straightening process. Through various experiments and simulations for the guide rail, we got the relationship between the loading stroke with different heat treatment and the loading stroke with cross section shape, and also the result of hardness testing curves and straightening stroke were discussed briefly. The quality and precision of straightness steel bar mainly depends on the results of hardness of heat treatment and microstructure of metal bar. Results put forward to the best method of selecting heat treatment methods and providing the theoretical basis for improving straightening precision and developing the optimal straightening process.
\end{abstract}

Keywords: SAE 52100 steel, heat treatments, straightening stroke, hardness test, microstructure

Cite This Article: MI Aye Su Khaing, and LU Hong, "Research on the Precision Straightening Stroke of SAE 52100 Steel in Different Heat Treatments." American Journal of Mechanical Engineering, vol. 2, no. 2 (2014): 41-46. doi: 10.12691/ajme-2-2-2.

\section{Introduction}

SAE 52100 Steel has carbon content of $0.93-1.1 \%$ and the most common form of steel as it's provides the material properties that are acceptable for many applications such as rotating devices, engineering tools, dies, vehicles, other domestics and machine manufacturing applications. Steel is mainly an alloy of iron and carbon, where other elements are present in quantities too small to affect the properties. Steel with low carbon content has the same properties as iron, soft but easily formed. As carbon content rises, the metal becomes harder and stronger but less ductile and more difficult to weld [1].

Guide rails are one of the most important components in terms of equipment because the quality of linear rail influences on the precision linear motion. Because of these reasons, it must be strong enough to take the downward force during high power load applied without excessive bending [3]. So, the reliability of the mechanical applications depends on the strength of the guide rail. However, without heat treatment, the guide rail cannot be attained the required hardness properties.

The process of heat treatment is carried out firstly by heating the metal after that cooling it in water or oil or air. The purpose of heat treatment is, to enhance the transformation of austenite to martensite i.e., (soft material to hard material), to change the grain size, to modify the structure of the material and relive the stress set up in the material. The various heat treatment processes are laser heat treatment, annealing, tempering, normalizing, hardening and quenching.

The straightness affected by machining and the heat treatment processing are one of the key performance parameter for the guide rail. The straightening process is a metal forming technique to improve the geometric quality of product such as straightness and precision [1]. The straightening technology is one of the most important processes in the manufacturing industry. Therefore, the main aim of this work is to analyze the mathematical calculation result of the precision straightening stroke of SAE 52100 steel in different heat treatments [5]. This research can be helpful to extend its life, easy to replacement and significant economic benefits.

\section{Material and Methods}

The chemical composition of test sample of the high carbon chromium bearing steel is shown in Table 1 which reveals that its equivalent grade agrees with AISI - 52100, GCr15 steel standard specification $[2,6]$. The samples are LG 15 and LG 25 series linear guide rail made of SAE 52100 were cut with the wheel cutting machine to get the desired length and used water spray cools the cutting tool cannot to change the original shape. Figure 1 shows the cross-sectional sizes of the samples for experiment.

Table 1. Chemical Constitution of SAE 52100 wt (\%)

Table 1. Chemical Constitution of SAE 52100 wt (\%)
\begin{tabular}{|c|c|c|c|c|c|c|c|}
\hline & $\mathrm{C}$ & $\mathrm{Mn}$ & $\mathrm{Si}$ & $\mathrm{Cr}$ & $\mathrm{P}$ & $\mathrm{S}$ & $\mathrm{Cu}$ \\
\hline Mat: & $0.93-$ & $0.25-$ & $0.15-$ & $1.3-$ & $\leq$ & $\leq$ & $\leq$ \\
Speci: & 1.1 & 0.45 & 0.65 & 1.6 & 0.027 & 0.02 & 0.35 \\
\hline
\end{tabular}




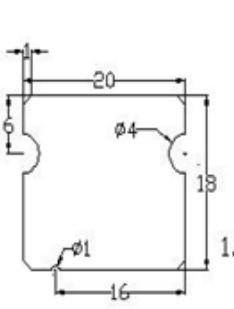

(1)

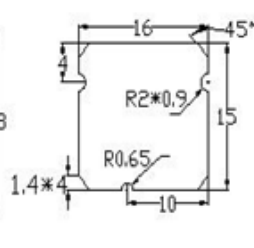

(2)

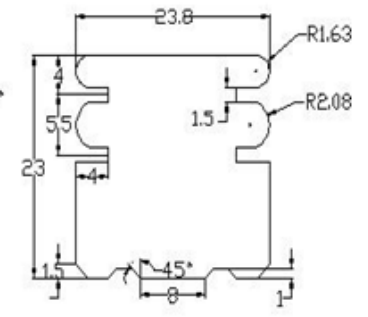

(3)
Figure 1. The Samples for Heat Treatments

\subsection{Test Specimen Preparation}

A high carbon chromium bearing steel with carbon content of $0.93-1.1 \%$ carbon is used in this study. The specimens were then prepared for hardness test and bending testing using a standard format of ASTM. Bending tests were carried out by a Model INSTRON1341 electro-hydraulic servo testing machine using prepared specimens.

\subsection{Heat Treatments of the Specimen}

Standard heat treatment procedures adapted the specimens to heat treat. Three different cross-sectional size samples were prepared for each of the operation and the average values were calculated based on the analysis was made. Some of the conventional heat treatment procedures chosen such as: annealing, tempering and laser heat treatment.

\subsubsection{Laser Heat Treatment}

Heat treating laser allows selective surface hardening against wear with little or no distortion of the component. Because this eliminates much part reworking that is currently done, the laser system's capital cost is recovered in a short time. This research paper is using $\mathrm{CO}_{2}$ laser heat treatment because the maximum carbon content is more than $1 \%$ [9]. The scanning speed is uniformly distributed for the three samples. As shown in Figure 1, sample No. 1 was using laser heat treatment with three different temperature values.

\subsubsection{Annealing Heat Treatment}

Annealing heat treatment in material science is a heat treatment that alters a material to increase its ductility and to make it more workable. It involves heating a material to above its critical temperature, maintaining suitable temperature and then cooling. Annealing can induce ductility, soften material, relieve internal stress, refine the structure by making it homogenous, and improve cold working properties [7]. Temperature for annealing heat treatment ranges between $675^{\circ} \mathrm{C} \sim 815^{\circ} \mathrm{C}$.

\subsubsection{Tempering Heat Treatment}

Tempering, consists of reheating quenched steel to a suitable temperature below the transformation temperature for an appropriate time and cooling back to room temperature. This process allows microstructure modifications to reduce the hardness to the desired level while increasing the ductility. By using temper heat treatment, the results can be given in a desired combination of hardness, ductility, toughness, strength and structural stability. The desired properties and structures depend on tempering temperature and time. In tempering heat treatment, temperature ranges between $200^{\circ} \mathrm{C} \sim 650^{\circ} \mathrm{C}[4]$.

\subsection{Mechanical Testing}

After these treatments, mechanical properties specimens were examined of the i.e. hardness, bending test and deformation of the material.

\subsubsection{Hardness Test}

The hardness of heat treated samples was evaluated using a Vickers Hardness (HX-1000 TM) tester. Prior to testing, the steel specimens was mounted using phenolic powder, grinded with 600 grit paper and polished to obtain a smooth surface finish. A direct load of 100gf was thereafter applied on the specimen for a dwell time of 10 seconds and diamond indenter is used for test. The hardness values are taken corresponding to the diagonal length of the indentation.

\subsubsection{Bending Test}

The specimens of heat treatment were tested on Model INSTRON1341 electro-hydraulic servo testing machine. The Bending test is used to demonstrate the relation between the load, span dimension and deflection of specimen. To investigate different having one end of the test piece, both ends fixed and no end fixed. The test pieces for bending experiment are of different dimensions, so we can determine the relation between the moment of inertia and dimension of samples. The load capacity of testing machine has $1000 \mathrm{kN}$ and stroke actuator is $\pm 75 \mathrm{~mm}$ and the load precision relative error is less than $0.5 \%$. The loading part in the middle is moved at the speed of the $0.6 \mathrm{~mm} / \mathrm{sec}$. After unloading, the residual deflection of the beam $\delta_{\mathrm{c}}$ is obtained by the displacement sensor.

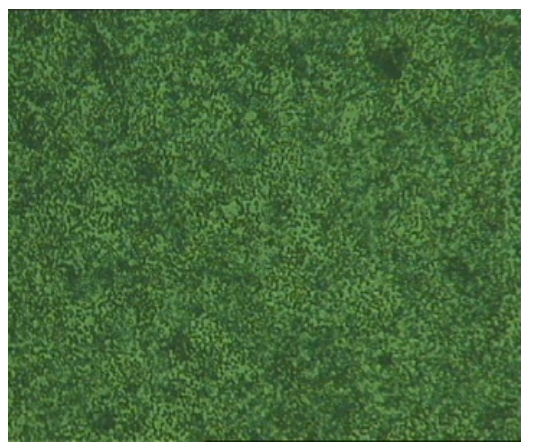

Figure 2. a) Laser Heat Treatment with initial temperatur

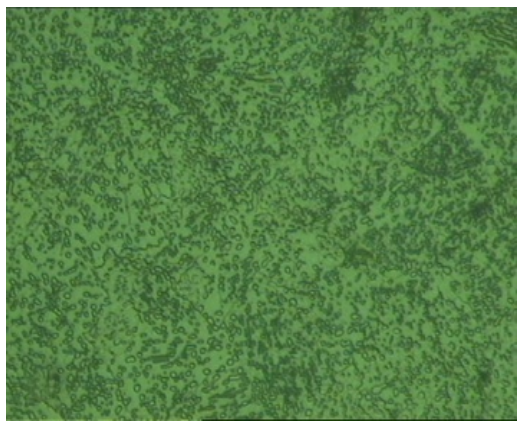

Figure 2. b) Laser Heat Treatment with Low Temperatur 


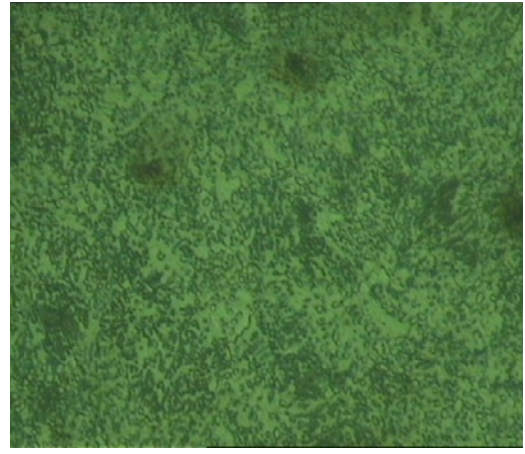

Figure 2. c) Laser Heat Treatment High Temperature

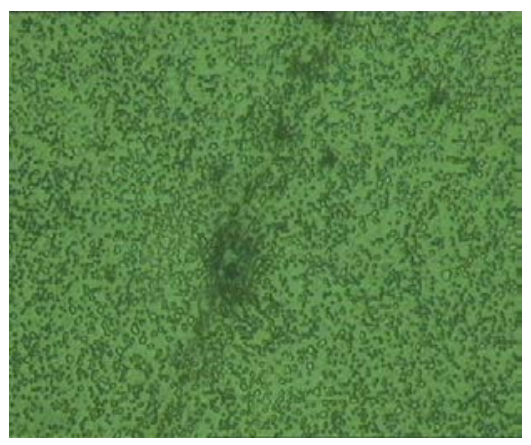

Figure 3. a) Annealing Heat Treatment

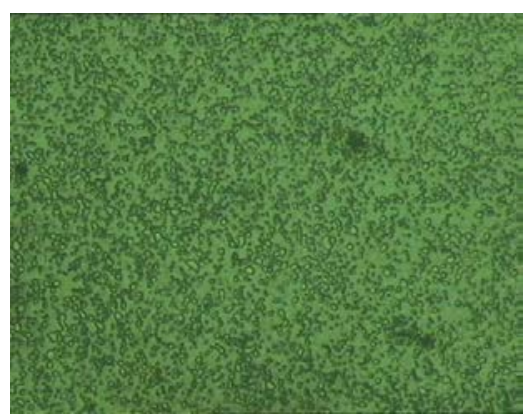

Figure 3.b) Tempering Heat Treatment

\section{Microstructural Analysis}

The change of microstructure in the material due to heat treatments is the main reason for the improved mechanical properties. Hence the microstructure examination is carried out to find the crystalline structure of after different heat treatments. Samples were prepared by conventional methods of sectioning followed by grinding, mechanical polishing and etching. The samples were polished using paper of grit and velvet cloth. These samples are etched with nital and dried in air. Microstructural analyses were carried out on some of the heat treated guide rail samples using an optical microscope [4]. The cross sections of the guide rails were taken for analysis. Mechanical properties were assessed using standard procedures. The results are contained in Plates 1 to 5 as shown in Figure 2 - Figure 3.

(Figure 2b) shows the metallographic structure of laser low heat treatment. The micrograph plate has the ferrite structures are fined pearlite, martensite, retained austenite and same size uniformly distributed [8]. The microstructure for laser high heat treatment $\left(1150^{\circ} \mathrm{C}\right)$ condition is shown in (Figure 2c). The effectiveness of heat treatment process is refining and homogenizing the structure. It has martensite and large amount of pearlite (black) structure. The propertis of martensite which is formed in carbon steels by the rapid cooling (quenching) of austenite at such a high rate that carbon atoms do not have time to diffuse out of the crystal structure in large enough quantities to form cementite $\left(\mathrm{Fe}_{3} \mathrm{C}\right)$.

Cementite, also known as iron carbide, is a chemical compound of iron and carbon, with the formula $\mathrm{Fe}_{3} \mathrm{C}$ (or $\mathrm{Fe}_{2} \mathrm{C}: \mathrm{Fe}$ ). By weight, it is $6.67 \%$ carbon and $93.3 \%$ iron. It has an orthorhombic crystal structure. It is a hard, brittle material, normally classified as a ceramic in its pure form, though it is more important in metallurgy. The metallographic structure of annealing heat treatment is shown in (Figure 3a). As it can be seen the cementite grains that is very hard and brittle which is easy to fracture [11]. The deformed structure was fully homogenized and the final microstructure consisted of fine ferrite grains in which the pearlite was more uniformly distributed.

(Figure $3 \mathrm{~b}$ ) shows the microstructure of tempering heat treatment at $215^{\circ} \mathrm{C}$. The spheroidizing carbide microstructures are the most homogenous in distribution and finest in sizes. By heating at this temperature pearlite, which is the lowest energy arrangement of steels, gets converted to ferrite and cementite [10]. It means that tby giving tempering heat treatment, the properties of material is changing from ductile to high hardness and low brittle. Ferrite is a ceramic-like material with magnetic properties that are useful in many types of electronic devices. Ferrites are hard, brittle, iron-containing, and generally gray or black and are polycrystalline-i.e., made up of a large number of small crystals. They are composed of iron oxide and one or more other metals in chemical combination. The steel after tempering heat treatment had the required standard hardness properties, by composing that crystallization. The structure is spherodized one thousand times larger than those of pearlite. This means that the spherodite steel is extremely ductile.

Hardness is a characteristic of a material, not a fundamental physical property. It is defined as the resistance to indentation, and it is determined by measuring the permanent depth of the indentation. The Vickers hardness test method is also referred to as microhardness test method is mostly used for small parts, this sections, or case depth work. The Vickers method is based on an optical measurement system. It is very useful for testing on a wide type of material as long as a test samples are carefully prepared. Figure 4 demonstrates the curves for Vickers hardness testing for the different crosssectional shape of specimens.
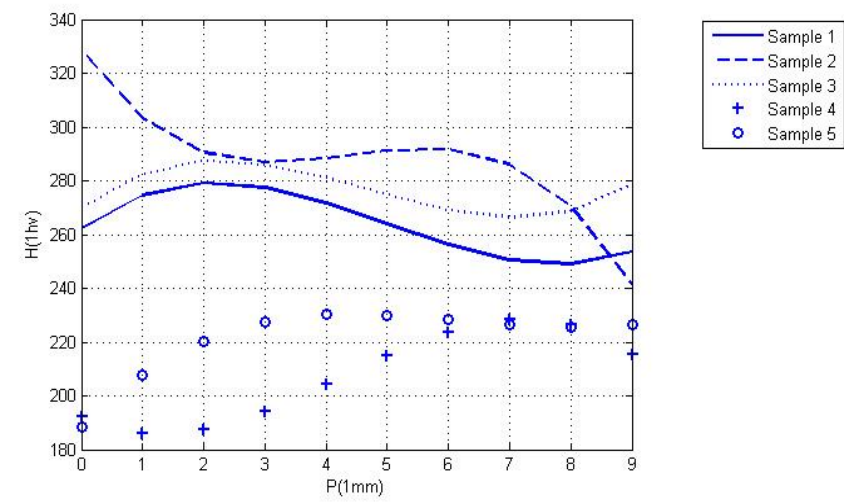

Figure 4. Curves of Vickers Hardness Testing 
The changes of microstructure in metallographic occur at different grain structures and properties. As shown in Figure 4, the five sample curves mean sample No. 1 is for the laser heat treatment with high temperature, sample No. 2 is tempering heat treatment, sample No 3 means annealing heat treatment, sample No. 4 is laser heat treatment and sample No. 5 is the laser heat treatment with initial temperature. According to the investigation of the hardness measurement, the highest hardness for sample (2) composed of finest carbide and martensite. Moreover, the spherodized carbides are also homogenous distribution. Properties of martensite and fined carbide can reduce wear resistance and improve the hardness. Sprerodized structure increases the ductility and machinability of the high carbon material. According to the discussions and Sample 2 structures are composing with high hardness. So, we can remark the sample No. 2 tempering heat treatment is the highest hardness according to the investigation of metallographic structure and Vickers hardness testing.

\section{Mathematical Calculation of Load- Stroke Model}

In this study, bending test is used to demonstrate the relation between the load and straightening stroke for mechanical testing. According to the investigation of microstructure and hardness testing, tempering heat treatment is the most proper for the bending test experiment because the metallographic properties of its heat treatment are high hardness, easy to machinability and ductility. So, after tempering heat treatment the specimen was applied for the bending test experiment.

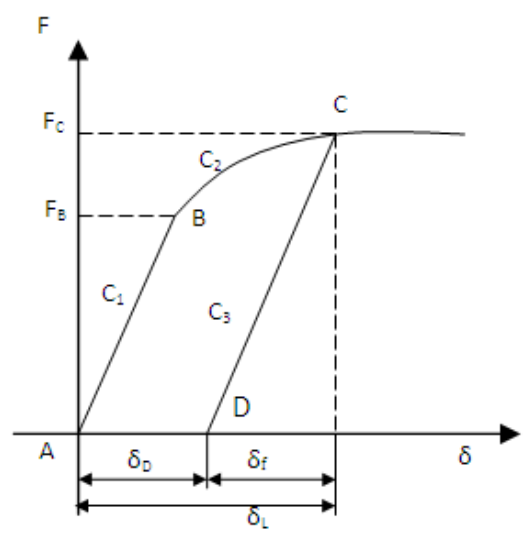

Figure 5. Load-Stroke Model of Rail

\subsection{Establishment of Load-Stroke Model}

In the bending test, three point reverse bending test was using. Pressure straightening is essentially a plastic antibending metal workpiece process. In the model of the traditional pressure straightening method, the straightening stroke prediction can be described by the metal elastic-plastic graphic and the mathematical formula. The impact of the Bauschinger effect is also neglected. Figure 5 shows a general load-stroke $(F-\delta)$ curve model for the three-point bending process, where two ends of a shaft are simply supported and the load can be applied to any point of a shaft. In the load-stroke model, we can approximate the elastic region during loading process to line $\mathrm{C}_{1}$, the plastic region to the line $\mathrm{C}_{2}$, and elastic region during unloading process to the line $\mathrm{C}_{3}$. Point $\mathrm{B}$ is the yield point for the elastic stage. Since the line $C_{3}$ is in the elastic unloading region, the line $\mathrm{C}_{3}$ can be assumed to be parallel to the elastic loading line $\mathrm{C}_{1}$. It means that $\mathrm{K}$ is the same constant value for the loading stages. $\delta_{\mathrm{L}}$ is the maximum loading stroke and $\mathrm{F}_{\mathrm{c}}$ is the maximum load. $\delta_{\mathrm{f}}$ is the springback stroke caused by elasticity during unloading process. Therefore, the permanent deflection $\delta_{\mathrm{D}}$ can be controlled by evaluating the springback.

\subsubsection{The Elastic Loading and Unloading Stage}

In Figure 2, the load-stroke relationship in the elastic loading stage, $\mathrm{C}_{1}$ line is expressed as

$$
\mathrm{F}=\frac{6 \mathrm{EI}}{l^{3}} \delta, 0<\mathrm{F} \leq \mathrm{F}_{\mathrm{B}},
$$

The load-stroke relationship in the elastic unloading stage, $\mathrm{C}_{3}$ line is expressed as

$$
\mathrm{F}=\frac{6 \mathrm{EI}}{l^{3}}\left(\delta-\delta_{0}\right), 0<\mathrm{F} \leq \mathrm{F}_{\mathrm{C}},
$$

Where, $\mathrm{F}$ is the load, $\delta$ is the stroke, $\delta_{0}$ is the initial deflection. I is the moment of inertia for the rectangular guide rail. So, we could be calculated by the following formula. The rail section has dimensions of height, $\mathrm{h}=$ $23 \mathrm{~mm}$, width, $\mathrm{b}=23.8 \mathrm{~mm}$ and the total span length $2 \mathrm{l}=$ $200 \mathrm{~m}$.

$$
\mathrm{I}=\frac{\mathrm{bh}^{3}}{12}=24131.217 \mathrm{~mm}^{4},
$$

Where, $\mathrm{b}$ and $\mathrm{h}$ are the width and height of the sample.

\subsubsection{The elastic-plastic loading stage}

In the elastic-plastic loading stage, according to the bending stress-strain relationship of the guide rail, the moment $\mathrm{M}$ is given by

$$
\mathrm{M}=\mathrm{M}_{\mathrm{t}}\left(1.5-0.5 \xi^{2}\right),
$$

The plastic bending ratio is given by

$$
\overline{\mathrm{M}}=\frac{\mathrm{M}}{\mathrm{M}_{\mathrm{t}}}=1.5-0.5 \xi^{2},
$$

Where $\mathrm{M}_{\mathrm{t}}$ is the elastic ultimate moment and $\xi$ is the elastic region ratio $\xi \in([0,1])$, which is the rate of the thickness of the elastic-plastic juncture to the thickness of the section. When $\xi=1$, it is purely elastic bending stage and $\bar{M}=1$; when $\xi=0$, it is at the elastic-plastics limit bending stage and $\bar{M}=1.5$.

At the elastic-plastic loading stage, according to the bending stress-strain relationship of the guide rail and the material property, and by analyzing the relationship between deflection and curvature in the elastic-plastic deformation, the pushdown stroke $(\delta)$ at the middle point of the guide rail can be expressed as

$$
\delta_{\mathrm{L}}=\frac{\mathrm{M}_{\mathrm{t}}}{3 \mathrm{EI}} \frac{l^{2}}{\overline{\mathrm{M}}^{2}}[5-(3+\overline{\mathrm{M}}) \sqrt{3-2 \overline{\mathrm{M}}}], \overline{\mathrm{M}} \in[1,1.5],
$$


The limit loads in different stages can be expressed as

$$
\begin{gathered}
\mathrm{F}_{\mathrm{B}}=\frac{2 \mathrm{M}_{\mathrm{t}}}{l}, \\
\mathrm{~F}_{\mathrm{C}}=\frac{2 \mathrm{M}_{\mathrm{t}}}{l} \overline{\mathrm{M}},
\end{gathered}
$$

Where, $\delta_{\mathrm{L}}$ is the value of loading stroke; $\delta_{\mathrm{D}}$ is the value of initial deflection, $\mathrm{E}$ is elastic modulus for the material, I is sectional moment of inertia, $l$ is half of span. $F_{B}$ is the limit load for elastic; $F_{C}$ is the limit load for elasticplastic. $\bar{M}$ is plastic-bending ratio and $M_{t}$ is the elastic ultimate moment. Based on the LG series guide rail, the properties of material and parameters are as followed: the elastic modulus, $\mathrm{E}=190089 \mathrm{MPa}$, span, $2 l=200 \mathrm{~mm}$. The contrast result calculation of stroke is shown in Table 2 .

Table 2. Contrast Result for Calculation of Deflection and Straightening Stroke of Tempering Heat Treatment Samples

\begin{tabular}{|c|c|c|}
\hline $\begin{array}{c}\text { Initial Deflection, } \delta_{0} \\
(\mathrm{~mm})\end{array}$ & $\begin{array}{c}\text { Straightening Stroke, } \\
\delta_{\mathrm{L}}(\mathrm{mm})\end{array}$ & $\begin{array}{c}\text { Applied Load, } \\
\mathrm{N}\end{array}$ \\
\hline 0.02 & 0.7596 & 20355.62 \\
\hline 0.03 & 0.7984 & 20900.57 \\
\hline 0.07 & 0.8745 & 22141.83 \\
\hline 1 & 0.9238 & 22673.01 \\
\hline 0.11 & 0.9388 & 22810.63 \\
\hline 0.2 & 1.0570 & 23586.47 \\
\hline 0.25 & 1.1149 & 23804.19 \\
\hline 0.3 & 1.1698 & 23939.05 \\
\hline 0.32 & 1.1911 & 23974.83 \\
\hline 0.4 & 1.2736 & 24043.63 \\
\hline 0.42 & 1.2937 & 24047.28 \\
\hline & & \\
\hline
\end{tabular}

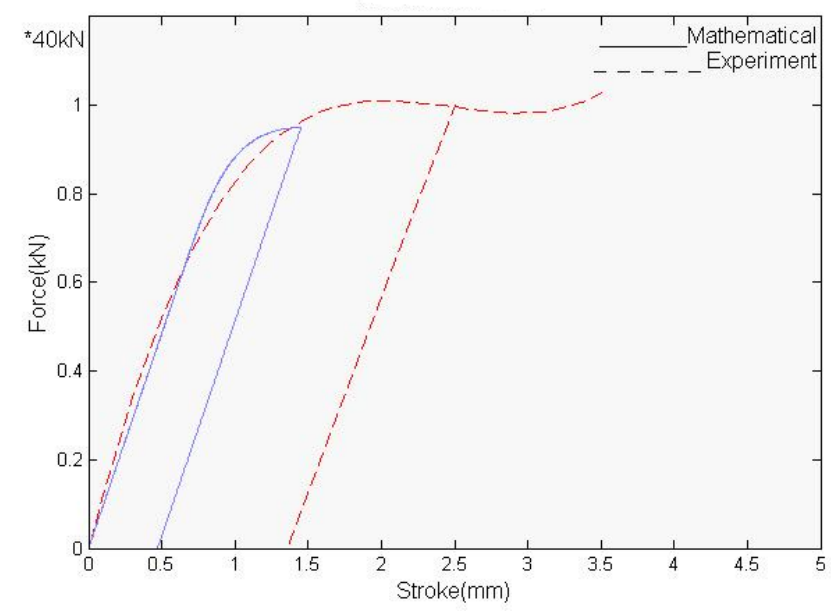

Figure 6. Contrast Curves for Load-Stroke Model

\subsection{Bending Experimental Test}

To verify the load-stroke model, experiments are carried out respectively on the Model INSTRON1341 electro-hydraulic servo testing machine. The principle of the experimental process is applying bending load through the punch stroke to cause the plastic deformation of the rail. The guide rail is supported at both ends with two fulcrums or supporters are arranged symmetrically on both sides of the loading part. The loads are applied on the surface of the beam and $2 l$ is the distance between the supporters. The whole process was working with the computer and its control software. During the test, the load capacity of testing machine has $1000 \mathrm{kN}$ and stroke actuator is $\pm 75 \mathrm{~mm}$ and the load precision relative error is less than $0.5 \%$. The loading part in the middle is moved at the speed of the $0.6 \mathrm{~mm} / \mathrm{sec}$. After unloading, the residual deflection of the beam $\delta_{\mathrm{c}}$ is obtained by the displacement sensor. Therefore, the stroke and the corresponding residual deflection could be used to analyze the bending process and properties with the data processing.

From the metal elastic-plastic curve and the formula, the straightening load- stroke model of linear guide rail can be calculated through mathematic model. As shown in Figure 6, we can get the contrast load-stroke model for the experimental and mathematical calculation result. From the mathematical calculation result, the max straightening stroke is $1.2937 \mathrm{~mm}$ each time, and the guide rail may otherwise be broken down. So, the guide rail can be straightened in a multi-step style.

\section{Conclusions}

In this paper, we can conclude according to the investigation of metallographic structure and hardness test based on different heat treatments and cross-sectional shape. The specimen for tempering heat treatment is the highest hardness, ductility and easy to machinable. Based on the heat treatment results, bending test experiment was carried out using the tempering heat treated specimen.

The load-deflection model is used for the analysis based on elasto-plastic mechanics theory. To verify the model, experimental researches are carried out on INSTRON1341 electro-hydraulic servo testing machine. And also to validate the accuracy and precision of the mathematical calculation and experimental results are also supported for this study. Theoretical model of this paper is directly calculated according to the initial deflection of the workpiece. The load-stroke curves calculated with the elasto-plastic theory are almost the same trend with the theoretical model and there has any error because of the actual material properties using for the experimental research. The value of material properties for the workpiece is really important to be considered in the mathematical calculation method. Based on the assumptions of the values, the springback stroke will be varied. Therefore, we can be concluded according to the result of mathematical calculation and experimental results with theoretical model are almost the same trend. So, it can be enhanced the accuracy and precision of the analytical and mathematical calculations to be developed the automatic straightening machine reference.

\section{Acknowledgement}

This paper was supported by the National Natural Science Foundation of China (NO. 51275372) and Wuhan High-Tech Development Project Foundation (NO. 201110921299).

\section{References}

[1] Hong, L., Ling H., and Leopold J., "Improvement on Straightness of Metal Bar Based on Straightening Stroke-Deflection Model", Science in China Series E: Technological Science, 52. 1866-1873. Jul. 2009. 
[2] Song, Y., and Yu, Z., "Load -Deflection Relations of T-Section Rails under Lateral Loads", Journal of Theoretical and Applied Mechanics, 51. 195-202. 2012.

[3] Graziella, K., Siegert J., and Westkamper, E., "Procedure to Improve The Understanding of The Rotating Straightening Process", Journal of Machine Enginnering, 2. 570-576. 2011.

[4] Ho-Lee, S., Ko-Lee, S., and Kim, Byung-Min., "Study on Manufacturing Process of Precision Linear Guide Rail through Shape Rolling and Shape Drawing", Journal of Mechanical Science and Technology, 24. 1647-1653. 2010.

[5] Yasir, Ali S., and S. Al-Ansari, L., "Studying Effect of Cooling Rate on the Linear, Non-Linear Deflection and Elastic Properties of Stainless Steel Beams", Intternational Journal of Applied Science and Technology, 2. 820-829. Oct. 2012.

[6] Kosel, F., Videnic, T., and Kosel, T., "Elasto-Plastic Springback of Beams Subjected to Repeated Bending/Unbending Histories", Journal of Material Engineering and Performance, 20. 846-854. Aug. 2011.
[7] Jing, Y., Ding-Fei, Z., and Xiao- Hong, W., "The Mathematical Model of Tension Straightening Process of Magnesium Alloy and Experimental Validation", Journal of Magnesium and Alloys, 1. 76-81. 2013.

[8] Hua, Z., and Huayong, Z., "Crankshaft Online Straightening Technology Determination System Based on Weighted Evaluation Function", International Journal of Graphic and Signal Processing, 2. 37-43. 2011.

[9] Yang, Shyue-Cheng., "Computerized Design Rollers with Straightening Bar", Journal of Material Transaction, 7. 560-565. 2010.

[10] Clemons, K., Lorraine, C., Salgendo, G., Taylor, A., Orgen, J., Umin, P., "Effects of Heat Treatment on Steels for Bearing Applications", Journal Material and Engineering Performance, 16. 515-520. 2007.

[11] Fadare, D. A., Fadara, T. G., Akanbi, T. G., "Effect of Heat Treatment on Mechanical Properties and Microstructure of NST 37-2 Steel" Journal of Minerals and Material Characteristics and Engineering, 10. 299-308. 2011 